\title{
Secondary school teachers' experiences of supporting mental health
}

Article

Accepted Version

Shelemy, L., Harvey, K. and Waite, P. (2019) Secondary school teachers' experiences of supporting mental health. Journal of Mental Health Training, Education and Practice, 14 (5). pp. 372-383. ISSN 1755-6228 doi:

https://doi.org/10.1108/JMHTEP-10-2018-0056 Available at https://centaur.reading.ac.uk/84491/

It is advisable to refer to the publisher's version if you intend to cite from the work. See Guidance on citing.

To link to this article DOI: http://dx.doi.org/10.1108/JMHTEP-10-2018-0056

Publisher: Emerald Publishing

All outputs in CentAUR are protected by Intellectual Property Rights law, including copyright law. Copyright and IPR is retained by the creators or other copyright holders. Terms and conditions for use of this material are defined in the End User Agreement.

\section{www.reading.ac.uk/centaur}

\section{CentAUR}

Central Archive at the University of Reading 
Reading's research outputs online 


\section{emerald PUBLISHING \\ Journal of Mental Health Training, Education and $\mathrm{P}_{\mathrm{I}}$}

\section{Secondary school teachers' experiences of supporting mental health}

\begin{tabular}{|r|l|}
\hline Journal: & Journal of Mental Health Training, Education and Practice \\
\hline Manuscript ID & JMHTEP-10-2018-0056.R1 \\
\hline Manuscript Type: & Research Paper \\
\hline Keywords: & $\begin{array}{l}\text { Teachers, Qualitative, School, Interpretative phenomenological analysis, } \\
\text { Adolescence, Mental Health }\end{array}$ \\
\hline \multicolumn{2}{|l}{} \\
\hline
\end{tabular}

\section{SCHOLARONE ${ }^{\text {m }}$ \\ Manuscripts}




\section{Secondary school teachers' experiences of supporting mental health}

2

3 Purpose: Teachers are often the first contact for students with mental health difficulties. They

4 are in an ideal position to identify students who are struggling and frequently support them

5 using different approaches and techniques. This qualitative study aims to investigate secondary

6 school teachers' experiences of supporting the mental health of their students.

7 Methodology: 7 secondary school teachers from state-funded schools in the UK participated in

8 face-to-face semi structured interviews. Interpretative phenomenological analysis was used to

9 understand and structure the data into themes.

10 Findings: Five superordinate themes emerged from the data analysis: Perceived role of teacher, 11 nature of relationship, barriers to helping the child, amount of training and resource, and 12 helplessness and satisfaction. Participants described the lack of training, resource and clarity 13 about their role to be causes of frustration. Internal and environmental factors often influenced 14 participants' feelings of helplessness.

15 Research limitations/implications: The findings from this study cannot be readily 16 generalised to the wider population due to the nature of qualitative interviews.

17 Practical implications: This study has led to a greater understanding of the experiences of 18 teachers within a school setting. It is crucial that mental health training for teachers 19 directly meets their needs and abilities.

20 Originality/value: This paper finds value in recognising the lived experience and 21 difficulties faced by teachers supporting students' mental health problems. A theoretical 22 model novel model-is presented based on this analysis that can help inform best practice 23 for schools. 
26 The amount of time teachers spend in contact with students makes them well placed to notice 27 symptoms and behaviours associated with internalizing and externalising disorders-difficulties 28 such as irritability, social withdrawal and changes in concentration (Ginsburg and Drake, 2002;

29 Chatterji et al., 2004). Teachers working in secondary schools are faced with a high prevalence 30 of mental health problems in their students. In the UK, two-thirds of ehildren and adolescents 31 with diagnosable mental health disorders have spoken to a teacher about their mental health 32 (Newlove-Delgado et al., 2015). Teachers are in an ideal position to refer and signpost students to mental health care services (Fazel et al., 2014). They are often the first point of contact for parents who are worried about their child's emotional wellbeing (Sax and Kautz, 2003; Ford 35 et al., 2008).

36 Many teachers acknowledge their ability to identify students who are in difficulty and 37 manage mental health problems in the classroom-(Rothì, Leavey and Best, 2008; Andrews, McCabe and Wideman-Johnston, 2014) and the link between academic and emotional health outcomes (Kidger et al., 2009). However without training, teachers have low confidence in 40 their knowledge and ability to recognise mental health problems, as well as providing support 41 within school (Roeser and Midgley, 1997; Walter, Gouze and Lim, 2006; Moor et al., 2007; 42 Andrews, McCabe and Wideman-Johnston, 2014). Previous studies have found teachers often feel uneasy when discussing mental health with students and are unsure how to manage emotional difficulties in the classroom (Roeser and Midgley, 1997; Walter, Gouze and Lim, 2006; Cohall et al., 2007; Moor et al., 2007).

46 There is a demand from governmental bodies in response to public campaigns

47 for secondary school teachers in the UK to have increased mental health knowledge and

training (Department of Health, 2015; Department of Health and Department of Education, 
51 programmes that train school staff around mental health (Anderson et al., 2018). However tFo

52 date, few studies have explored teachers' beliefs about specific aspects relating to students' 53 mental health, and their role in supporting students. A holistic understanding of teachers' lived 54 experience of students' mental health problems is needed to facilitate the design of resources 55 and training that may best support teachers (Kirkpatrick, 2008). By learning about the 56 experiences teachers have had regarding mental health in schools, intervention developers can 57 optimally design interventions and resources that may best help teachers in the future.

58 The present study

59 The aim of the current study is to explore teachers' perspectives of supporting students' mental 60 health, focusing on their emotional and cognitive processing of these experiences. The 61 rigorous, detailed and phenomenological exploration of the experiences of teachers will help 62 to better understand the impact of supporting students on participants' own beliefs and 63 emotions. The stuly uses the methodologieal framework of Interpretative Phenomenological Analysis (IPA) to generate a rigorous, detailed and in-depth exploration of the "lived experience' of individuals, thus enabling a rich understanding of paticipants's stories and perspectives (Smith, 2004). In the last decale IPA has been inereasingly used in qualitative healthreseareh, partieulaly when the topie is under stlie and patieipants' experienees have yet to be systematically explored (e.g. Fox and Diab, 2015; Smith and Rhodes, 2015). The present study aims to explore the experiences teachers have had regarding the 70 mental health of their students in schools. A better understanding of teachers' experiences, 71 needs and opinions can improve the development of future mental health interventions targeted at teachers (Han and Weiss, 2005; Neil and Christensen, 2009). 
75 The study uses the methodological framework of Interpretative Phenomenological Analysis

76 (IPA) to generate a rigorous, detailed and in-depth exploration of the 'lived experience' of

77 individuals, thus enabling a rich understanding of participants' stories and perspectives (Smith, 78 2004). In the last decade IPA has been increasingly used in qualitative health research, 79 particularly when the topic is under-studied and participants' experiences have yet to be 80 systematically explored (e.g. Fox and Diab, 2015; Smith and Rhodes, 2015). IPA employs a 81 systematic approach to analysis, which recognizes the role of the researcher as an interpreter 82 of the insights from the participant. IPA uses idiographic inquiry in which each participant's 83 story is analysed in detail and considered as an individual, separate narrative prior to exploring 84 commonalities across participant accounts (Smith, Harr and Van Langenhove, 1995; Smith, $85 \quad 2004)$.

86 Ethical approval for the study was granted by the University of Reading Research 87 Ethics Committee (reference number 2016-037-PW). The study used IPA and-was conducted

88 following established criteria for rigour in qualitative research (Denzin and Lincoln, 1994), 89 using the COREQ checklist for reporting (Tong, Sainsbury and Craig, 2007) (Appendix A).

90 SamplingParticipants

91 Participants were eligible for inclusion if they were a) secondary school teachers who 92 b) had experience of a conversation with at least one student about their mental health. We-alse 93 only recruited participants in the South East of England due to travel limitations of the research 94 team. The study was advertised via word of mouth and online social media (Twitter, Facebook) 95 snowballing distribution of information. Advertisements were shared from the personal and 96 university social media accounts, and subsequently 're-shared' by members of the public.

97 Eligible participants contacted the lead researcher and were contacted with further information 98 about the study. Nineteen people expressed interest in the study. From this pool of potential 99 participants, seven individuals met the inclusion criteria (reasons for exclusion: 5 people taught 
100 in primary schools, 7 people did not respond past initial contact). The number of participants 101 in the study was determined by the recommendation from Smith, Flowers and Larkin (2009)

102 that the number of interviews for an in-depth IPA analysis should be between four and ten.

103 Participants were seven teachers working in different secondary state schools in the South East

104 and London regions of the UK. There were five female and two male teachers and their ages 105 ranged from 24 to 53 years. Five participants were White British, one was Asian British and 106 for the remaining participant, ethnicity was not provided. Years of experience working as a 107 teacher ranged from 2 to 26 years.

108 Procedure

109 One-to-one interviews were conducted by the male lead author, a $\mathrm{PhD}$ student trained 110 in qualitative research methods at the University of Reading. The interviewer had no prior 111 relationship with the participants before the study. Interviews took place in a private room in 112 the teacher's school or the University of Reading. Participants gave their informed written 113 consent for their data to be included in the research. The interviews lasted between 38 to 84

114 minutes. Participants were reimbursed $£ 15$ for their time. Interviews were audio-recorded and 115 transcribed verbatim by the lead author. Detailed field notes were written by the lead researcher 116 following interviews and were used as an aid during analysis.

117 At the start of the interview participants were asked to think about a specific time that 118 they had supported a student who was struggling with mental health difficulties. Interviews 119 followed a semi-structured topic guide written by the authors and piloted with a secondary 120 school teacher by the lead author (Appendix B). The topic guide was used flexibly to explore 121 in depth the emotions, cognitions and beliefs felt by the participants when recalling their single 122 experience interacting with a student with a mental health problem.

\section{Data Analysis}


124 The data analysis was completed in several stages following the IPA framework (Smith et al., 125 2009). This methodology ensured an in-depth and idiographic analysis by focusing initially on

126 individual interviews and eventually working towards an overall categorisation of themes.

127 Firstly, the lead researcher (LS) read and re-read each transcript to ensure a high level of

128 familiarisation with the data. In the second stage, transcripts were independently coded into

129 nodes with interpretative annotations added that focused on the cognitive and emotional

130 experiences of the participant. The computer software package NVivo (QSR, 2014) was used

131 to facilitate coding of the transcribed data. After this idiographic approach, nodes from the

132 different interview transcripts were compared and linked. The following stage involved

133 grouping and organizing nodes into themes. Themes were discussed and questioned with two

134 further researchers $(\mathrm{KH}$, an experienced qualitative researcher \& $\mathrm{PW}$, an experienced

135 researcher into young people's mental health and a clinician) acting as independent auditors

136 (Smith, Flowers and Larkin, 2009). Superordinate themes were derived from the data following

137 an iterative processing and rearrangement of the themes until the authors felt that the data was

138 well represented.

$141 \quad$ Results

142 The interpretative analysis of the interviews resulted in five superordinate themes that are 143 shown presented in Table 1 and are explored further below. A map of the superordinate themes 144 and their relation to each other is presented in Table 2.

146 [Table 1 near here] 
149 Participants presented their role of a teacher as a 'balancing act' between adequately providing 150 support and facing the consequences of being too close to a student. All participants 151 acknowledged how they did not want to become a 'therapist', and yet still expressed difficulty 152 in knowing how close they should be to students. Going beyond the role of an educator.

154 All participants viewed their primary role as educators, with a focus on the academic 155 achievement of their students. It became clear that participants worried that they would be 156 giving incorrect advice if they were to advise students. it for them but ... I can have a discussion with him and then slowly they will start talking more and more and then hopefully calm - Participant 2 (P2); female

Some participants were unsure whether to support students suggesting a lack of clarity over their role as caregivers.

\section{I'm there to be a caregiver but like to a certain degree. I don't know} what the degree is yet - P5; female Consequences from being too close to students.

Many of the participants worried around boundaries and the consequences of being too close with students when discussing their mental health. Participants described-felt that they had difficulty maintaining a disciplinary role with a student whilst supporting them.

Things can go wrong very easily and very quickly and then as I found before ... my relationship with this child as a teacher was compromised because of the relationship that I had with the child as somebody who cared about her and that was not my role so I think I learnt a valuable lesson - P7; female 
Role of teacher to refer and signpost.

175 Some participants described how it is not their responsibility to support students directly but

176 that they felt they should be referring students to other appropriately trained professionals.

177 Several participants spoke about the mental health of their students in a medicalised way,

178 perceiving their problems as something that 'required fixing' by a health professional rather

179 than more holistically by the people around the young person.

It's not our responsibility. I think we're not trained to be counsellors

we should ... send them off, refer them to someone else cause we can't take responsibility. That's what I feel - P5; female

183 In contrast, other participants argued that in fact teachers can work collaboratively to support 184 a student.

It doesn't always have to become someone else's problem ... this is

189 Nature of relationship

190 Participants invested in the mental health of their students exhibited a parental-like caring and

191 sympathy. These participants described a more trusting relationship and found that this made

192 it easier for the young person to be open.

193 Conversations depend on good relationships.

194 Participants clearly emphasised that they felt trust was important in building a good relationship 195 with the young person. 
random members of the public. They find safe confiding people that they trust, so I did feel like this person trusts me - P5; female

201 Many of the participants spoke of how much they cared about the wellbeing of their students.

202 These participants tended to be those who considered student wellbeing as part of their role.

You know this person's come to you in trust and you want to you want to be there to help them because you know what it's taken for them to do that - P2; female

206 Several participants were protective over the young person, such as defending the student in 207 front of their parents. really annoyed at her mum for not quite realising how talented she is or how unique and special she is" - P1; female

212 The participants believed that mMany of the students supported by participants experienced 213 transitory and unstable lives at home and with their friendship groups. It was clear that 214 participants saw the school setting as one that can be consistent and secure for their students.

215 The participants spoke about their responsibility to provide this stable care as if they are 'in 216 loco parentis/in place of parents' whilst the student is in school.

217 We are a stable environment for her. We're somewhere where she 218 can come and get the support and have the family relationship that 219 she needs - P3; male

\section{Barriers to helping the young person}

221 All of the participants described various barriers to obtaining appropriate help for their 222 students. 
Amount of time or space.

224 All participants described how the pressures of time and space when working in a school were

225 barriers for them adequately supporting their students. When a student with a mental health 226 problem approached them, participants found that their academic commitments got in the way 227 of them feeling confident in providing good support being able to provide good support to the 228 student.

I felt frustrated as well because if I couldn't fix this in five to ten minutes then well then I couldn't fix it because I had to be somewhere else because the school timetable is so rigorous - P2; female

Working with other teams and services.

234 Participants described overburdened external services as a clear barrier for getting the young 235 person appropriate help. The NHS Child and Adolescent Mental Health Services' (CAMHS) 236 long waiting times and low referral rates was viewed by many participants as a problem that 237 often contributed to mental health decline in students.

I want action immediately. I understand that CAMHS and other professional agencies have longer waiting lists. I understand the cuts that they've gone through and I understand the frustrations they have but it doesn't stop still when you've got a young person in front of you crying out for help that you want to help them and I think you then pick up those frustrations - P6; male

245 Parents were occasionally seen as a source of difficulty and a contributing factor to the 246 student's poor mental health. Some participants described how parents' own beliefs and 247 cultural views about mental health stopped students from accessing appropriate help. This 
248 made it very difficult for participants to talk to the family about their child and try to

249 recommend services and strategies.

I think also we're not only having to deal with the mental health of the

\section{Amount of training and resource}

256 their students. Often participants reported a lack of understanding and knowledge about how

257 best to help. In various examples participants resorted to using 'common sense' and their 258 teaching skills to independently provide solutions.

Previous understanding about mental health.

Unanimously participants mentioned a lack of training and preparation to help students with mental health problems. Participants subsequently felt ill-prepared and unable to competently support students.

It was a case of trying to make a square fit a circle so with the training we had and with the resources we had trying to support them, it just felt very inadequate, it felt superficial the support we were giving and it didn't feel like we were actually supporting them in any real way - P7; female

Having to independently come up with ideas.

Frequently participants described having to support students doing what they instinctively thought was the right thing to do.

I just had to sort of rely on my natural teaching skills which is just to listen to her and to say to her is it's probably not as bad as you're 
making it out, it's all in your head, it's all in your mind, but a lot of the time what I was saying was probably not the right thing and she was getting more and more anxious - P2; female

\section{Helplessness and Satisfaction}

The emotions described by many participants were those of helplessness and feeling as though they had let down their students. On the other hand, there were participants who felt that they positively impacted their student's mental health and were glad to help. Sadness and Helplessness.

At times during the interview many participants became upset and emotional. When they perceived that theirir student was not showing signs of improvement or receiving appropriate support, some participants felt devastated. This was especially the case for those that had a strong empathetic investment in their student.

How do we feel? You do feel helpless ... you feel that you're losing a child - P3; male

The perceived lack of options for support or treatment for the young person led participants to feel that there was nothing else that they could do to improve the mental health of their student. Initially there was nothing there was nothing I could do, there was nowhere I could send her, there was no referral, there was nothing - P2; female

The culmination of not being able to adequately support a student together with other services' limited availability meant some participants felt as though they had failed in their role as a teacher.

I came into teaching to help young people to be more successful to change their lives for the positive and generally I've been successful in doing that but when you can't and when ... that 
support is either not there or they can't do it, that that's a horrible feeling - P4; female

\section{Frustration.}

301 The barriers to getting the student appropriate help combined with the participants' own lack

302 of knowledge and capability often contributed to feelings of anger and frustration. Participants

303 described aggravation at not being able to have resources within the school to support a high304 risk student.

There was nowhere I could put her, there was nowhere private I could take her ... so it was just very frustrating the kind of mental health support we were offering - P2; female

Satisfaction and hope from helping.

In the cases where participants felt that they had helped their students, they expressed a great deal of relief and satisfaction. Many participants were hopeful that their support would make a

311 positive change to the young person's life.

I just felt so pleased that I did it [helped]. I said to my daughter in

315 Some participants described their desperate hope that the mental health of their students would

316 improve. The quote below highlights the resilience and perseverance of the participant to help

317 his student and keep him safe in the face of various barriers and setbacks.

$318 \quad$ You just keep going and keep trying to help them so you hope that they're going to be in school on a Monday after a weekend and you hope that you get another chance of keeping them safe for another week and hoping that something is going to change that's gonna 
give them a better opportunity, give them better support. You just keep going - P3; male

\section{Discussion}

326 Semi-structured interviews were conducted with seven secondary school teachers in the UK.

327 The interviews explored participants' experiences of conversations with students concerning 328 their mental health. Five superordinate themes were generated exploring the different factors of participants' experiences.

Based on the findings from this study, we propose an interpretative and theoretical 331 model to represent $\theta$ f the experiences and perceptions of the participants (shown in Figure 1).

332 The emotional response from participants depended on their observed changes in the students' mental health and the extent of their own investment in the emotional health of the student.

334 The changes in the mental health of the student relied on two factors: a) the barriers to getting 335 the child appropriate help, and b) the internal knowledge and expertise of the teacher to help 336 the student. The participant's interest in the mental health of their students was determined by 337 how they themselves view the role of the teacher their closeness to students. These two streams:

338 a) the ability for the child to get appropriate help from the school, external services or the teacher themselves and b) the teacher's own investment in the student's mental wellbeing combine and impact on the emotional reaction of each participant.

$342 \quad$ [Figure 1 near here]

Many of the participants felt unable to successfully help their students and spoke as if

345 they had failed them. The helplessness described by participants included feelings of failure, 346 isolation and negative predictions for the student's future. This helplessness has previously 
347 been linked to the perceived 'ambiguity of the teacher's role' as highlighted in our own analysis

348 (Travers and Cooper, 1993). This helplessness is likely to impact on teachers' own wellbeing 349 and ability to work effectively as well as them feeling emotionally drained (Kidger et al., 2010).

350 A common generated theme was the lack of knowledge from participants about what 351 to do and the right way to respond to students with mental health difficulties. Several 352 participants viewed their student's mental health as a medical problem to be fixed. This has 353 potential to limit the perception of their own capacity to support them. This theme is held 354 consistently across similar studies, in which school teachers describe their lack of training or 355 knowledge to adequately support the mental health of their students (e.g. Walter, Gouze and 356 Lim, 2006; Kidger et al., 2009; Knightsmith, Treasure and Schmidt, 2013; Andrews, McCabe 357 and Wideman-Johnston, 2014). Many researchers and teachers themselves have emphasized 358 the importance of school staff receiving adequate training, information, and resources to 359 distribute to students with mental health problems (Roeser and Midgley, 1997; Reinke et al., 360 2011).

Participants' experience of helplessness was often attributed to poor communication 362 and input from external services, notably CAMHS. Similar UK studies have highlighted the 363 negative experience that teachers have had with external support services, such as the lack of 364 communication from CAMHS and external services' long waiting times (Ford and Nikapota, 365 2000; Rothi and Leavey, 2006). The time restrictions from the teaching profession on the 366 ability to support emotional issues in students has been repeatedly been reported by teachers in 367 previous research (Walter, Gouze and Lim, 2006; Williams et al., 2007). School-based 368 interventions may help staff feel able to not rely as heavily on external services and avoid the

$369 \quad$ identified barriers to providing support. 
Similarly, parents of students were often viewed as a barrier to helping the young

372 person. Other studies have identified that teachers find working with parents a frustrating

373 process in which parents are often perceived to be "uncooperative, disengaged, and unwilling

374 to take responsibility for their children's actions" (Williams et al., 2007; Knightsmith, Treasure

375 and Schmidt, 2013). In one questionnaire, teachers endorsed lack of parental involvement as a

376 barrier to getting help for their students (Walter, Gouze and Lim, 2006). Teachers have rated

377 problematic relationships with parents as the most common barrier to supporting students with

378 behavioural health difficulties (Ford and Nikapota, 2000).

379 Strengths and limitations

380 The qualitative method of this study enables a valid exploration of the issues that 381 concern teachers when discussing mental health in schools. The study met all of the 382 requirements of the COREQ guidelines for rigorous qualitative research (Appendix A). All of

383 the participants were practicing teachers with first-hand experience of mental health difficulties

384 in students and therefore in a position to contribute to the research question. Whilst

385 participants' specific experiences with students differed extensively, the themes that have been

386 generated were consistent across all those interviewed.

387 It is important to acknowledge the limitations encountered when conducting qualitative

388 research. Participants were teachers who expressed an interest in discussing their experiences

389 and were willing to give up their time to participate in the research. It would be useful to

390 investigate the experiences of teachers who have not had supportive interactions with their

391 students and are not interested in their mental health. The participants were all teachers within

392 schools with a 'Good' or 'Outstanding' Ofsted rating, meaning that their schools are deemed

393 above average in academic, social and behavioural ability. It would be of interest to future

394 research to learn more about teachers' experiences in lower-ability or lower-Ofsted rating

395 schools. Characteristically these schools are less financially flexible and so may present 
396 different experiences and problems for teachers. Likewise, the participants were all based in

397 schools in the South East of England. The demographic uniqueness of the sample has potential

398 to shape the data and their experiences. Going forward, further research should be conducted

399 with samples that differ in their geographic and demographic characteristics. This is important

400 to understand to what extent the interpretational model may be generalised to other school staff.

Whilst we intend that the current study has 'theoretical generalisability', in that the knowledge and understanding from these unique accounts may extend and be relevant to the

wider experiences of others, these results are not intended to be generalizable to the wider

410 population. It would be interesting to explore whether participants' experiences are shared by

411 other teachers, other support staff within the school, as well as the students themselves.

\section{Conclusion}

413 This paper aims to use an idiographic and experiential-driven qualitative analysis to

414 better understand the experiences of secondary school teachers in supporting the mental health

415 of their students. Participants from this study expressed a great deal of caring for their students,

416 but also a range of negative cognitions due to lack of training, resources and adequate 417 guidelines. These findings suggest that the emotional reaction of participants to these 418 experiences is determined by a) how they view their own role in relation to supporting their 419 students, and b) whether their student is receiving effective and informed help from the school, 
420 external services or from the teacher. This interpretation is presented as a model that can help

421 inform the design of future teacher-targeted mental health interventions.

422

423 Acknowledgments

424 We would like to thank the teachers who took part in this research for their help. The research 425 materials can be accessed by contacting the corresponding author.

426

427 References

428 Anderson, M. et al. (2018). 'Mental Health Training Programs for Secondary School

429 Teachers: A Systematic Review', School Mental Health, 1-20. doi: 10.1007/s12310-018-9291-2

430 Andrews, A., McCabe, M. and Wideman-Johnston, T. (2014) 'Mental health issues in the 431 schools: are educators prepared?', The Journal of Mental Health Training, Education and

432 Practice. Emerald Group Publishing Limited, 9(4), pp. 261-272.

433 Chatterji, P. et al. (2004) 'Cost assessment of a school-based mental health screening and

434 treatment program in New York City.', Mental health services research, 6(3), pp. 155-66.

435 Cohall, A. T. et al. (2007) 'Overheard in the halls: what adolescents are saying, and what

436 teachers are hearing, about health issues.', The Journal of school health, 77(7), pp. 344-50.

437 doi: 10.1111/j.1746-1561.2007.00218.x.

438 Denzin, N. K. and Lincoln, Y. S. (1994) Handbook of qualitative research. Sage

439 Publications.

440 Department of Health. (2015). Future in Mind - Promoting, Protecting and Improving Our

441 Children and Young People's Mental Health and Wellbeing. Retrieved from

442 https://assets.publishing.service.gov.uk/government/uploads/system/uploads/attachment data

$443 \quad$ /file/414024/Childrens Mental Health.pdf.

444 Department of Health and Department of Education. (2018). Government Response to the 
445 Consultation on Transforming Children and Young People's Mental Health Provision: a

446 Green Paper and Next Steps. Retrieved from

447 https://assets.publishing.service.gov.uk/government/uploads/system/uploads/attachment_data

448 /file/728892/government-response-to-consultation-on-transforming-children-and-young-

449 peoples-mental-health.pdf.

450 Fazel, M. et al. (2014) 'Mental health interventions in schools in high-income countries', The

451 Lancet Psychiatry. Elsevier, 1(5), pp. 377-387. doi: 10.1016/S2215-0366(14)70312-8.

452 Ford, T. et al. (2008) 'Predictors of Service Use for Mental Health Problems Among British

453 Schoolchildren', Child and Adolescent Mental Health. Wiley/Blackwell (10.1111), 13(1), pp.

454 32-40. doi: 10.1111/j.1475-3588.2007.00449.x.

455 Ford, T. and Nikapota, A. (2000) 'Teachers' attitudes towards child mental health services', 456 Psychiatric Bulletin. Cambridge University Press, 24(12), pp. 457-461. doi:

$457 \quad 10.1192 / \mathrm{pb} .24 .12 .457$.

458 Fox, J. R. and Diab, P. (2015) 'An exploration of the perceptions and experiences of living

459 with chronic anorexia nervosa while an inpatient on an Eating Disorders Unit: An

460 Interpretative Phenomenological Analysis (IPA) study', Journal of Health Psychology, 20(1), 461 pp. 27-36. doi: 10.1177/1359105313497526.

462 Ginsburg, G. S. and Drake, K. L. (2002) 'School-Based Treatment for Anxious African463 American Adolescents: A Controlled Pilot Study', Journal of the American Academy of Child 464 \& Adolescent Psychiatry, 41(7), pp. 768-775. doi: 10.1097/00004583-200207000-00007.

465 Han, S. S. and Weiss, B. (2005) 'Sustainability of Teacher Implementation of School-Based 466 Mental Health Programs', Journal of Abnormal Child Psychology. Kluwer Academic

467 Publishers-Plenum Publishers, 33(6), pp. 665-679. doi: 10.1007/s10802-005-7646-2.

468 Kidger, J. et al. (2009) 'Part and parcel of teaching? Secondary school staff's views on 469 supporting student emotional health and well-being', British Educational Research Journal. 
$470 \quad$ Routledge , 36(6), pp. 919-935. doi: 10.1080/01411920903249308.

471 Kirkpatrick, H. (2008) 'A Narrative Framework for Understanding Experiences of People

472 With Severe Mental Illnesses', Archives of Psychiatric Nursing, 22(2), pp. 61-68. doi:

$473 \quad 10.1016 /$ j.apnu.2007.12.002.

474 Knightsmith, P., Treasure, J. and Schmidt, U. (2013) 'We don't know how to help: an online 475 survey of school staff', Child and Adolescent Mental Health. Wiley/Blackwell (10.1111), 476 19(3), p. n/a-n/a. doi: 10.1111/camh.12039.

477 Moor, S. et al. (2007) 'Improving the recognition of depression in adolescence: Can we teach 478 the teachers?', Journal of Adolescence, 30(1), pp. 81-95. doi:

$479 \quad 10.1016 / \mathrm{j}$. adolescence.2005.12.001.

480 Neil, A. L. and Christensen, H. (2009) 'Efficacy and effectiveness of school-based prevention 481 and early intervention programs for anxiety', Clinical Psychology Review, 29(3), pp. 208482 215. doi: 10.1016/j.cpr.2009.01.002.

483 Newlove-Delgado, T. et al. (2015) 'Mental health related contact with education 484 professionals in the British Child and Adolescent Mental Health Survey 2004', The Journal 485 of Mental Health Training, Education and Practice. Emerald Group Publishing Limited, 486 10(3), pp. 159-169.

487 -NVivo qualitative data analysis Software- (2014). QSR International Pty Ltd.

488 Reinke, W. M. et al. (2011) 'Supporting children’s mental health in schools: Teacher 489 perceptions of needs, roles, and barriers.', School Psychology Quarterly, 26(1), pp. 1-13. doi: $490 \quad 10.1037 / \mathrm{a} 0022714$.

491 Roeser, R. W. and Midgley, C. (1997) 'Teachers' Views of Issues Involving Students' 492 Mental Health', The Elementary School Journal, 98(2), pp. 115-133. doi: 10.1086/461887. 493 Rothi, D. and Leavey, G. (2006) 'Child and adolescent mental health services (CAMHS) and 494 schools: Inter-agency collaboration and communication', The Journal of Mental Health 
495 Training, Education and Practice. Emerald Group Publishing Limited, 1(3), pp. 32-40.

496 Rothì, D. M., Leavey, G. and Best, R. (2008) 'On the front-line: Teachers as active observers

497 of pupils' mental health', Teaching and Teacher Education. Pergamon, 24(5), pp. 1217-

498 1231. doi: 10.1016/J.TATE.2007.09.011.

499 Sax, L. and Kautz, K. J. (2003) 'Who first suggests the diagnosis of attention-

500 deficit/hyperactivity disorder?', Annals of family medicine. American Academy of Family

501 Physicians, 1(3), pp. 171-4. doi: 10.1370/AFM.3.

502 Smith, J. A. (2004) 'Reflecting on the development of interpretative phenomenological

503 analysis and its contribution to qualitative research in psychology', Qualitative Research in

504 Psychology. Routledge, 1(1), pp. 39-54. doi: 10.1191/1478088704qp004oa.

505 Smith, J. A., Flowers, P. and Larkin, M. (2009) Interpretative phenomenological analysis :

506 theory, method, and research. SAGE.

507 Smith, J. A. and Rhodes, J. E. (2015) 'Being depleted and being shaken: An interpretative

508 phenomenological analysis of the experiential features of a first episode of depression',

509 Psychology and Psychotherapy: Theory, Research and Practice, 88(2), pp. 197-209. doi:

$510 \quad 10.1111 /$ papt.12034.

511 Smith, J., Harr, R. and Van Langenhove, L. (1995) 'Rethinking Methods in Psychology'.

512 London. doi: 10.4135/9781446221792.

513 Tong, A., Sainsbury, P. and Craig, J. (2007) 'Consolidated criteria for reporting qualitative

514 research (COREQ): a 32-item checklist for interviews and focus groups', International

515 Journal for Quality in Health Care. Oxford University Press, 19(6), pp. 349-357. doi:

516 10.1093/intqhe/mzm042.

517 Travers, C. J. and Cooper, C. L. (1993) 'Mental health, job satisfaction and occupational

518 stress among UK teachers', Work \& Stress, 7(3), pp. 203-219. doi:

$519 \quad 10.1080 / 02678379308257062$. 
520 Walter, H. J., Gouze, K. and Lim, K. G. (2006) 'Teachers' Beliefs About Mental Health

521 Needs in Inner City Elementary Schools', Journal of the American Academy of Child \&

522 Adolescent Psychiatry, 45(1), pp. 61-68. doi: 10.1097/01.chi.0000187243.17824.6c.

523 Williams, J. H. et al. (2007) 'Teachers' Perspectives of Children’s Mental Health Service

524 Needs in Urban Elementary Schools', Children \& Schools. Oxford University Press, 29(2),

525 pp. 95-107. doi: $10.1093 / \mathrm{cs} / 29.2 .95$.

526

527

528

529

530

531

532

533

534 


\begin{tabular}{|c|c|}
\hline Superordinate themes & Subordinate themes \\
\hline 1. Perceived role of teacher & $\begin{array}{l}\text { - Going beyond the role of an educator } \\
\text { - Consequences of being close to students } \\
\text { - } \text { Role of teacher to signpost and refer }\end{array}$ \\
\hline 2. Nature of relationship & $\begin{array}{l}\text { - Conversations depend on good } \\
\text { relationships } \\
\text { - Showing care and positive regard for the } \\
\text { student } \\
\text { - Ability to provide stable environment }\end{array}$ \\
\hline 3. Barriers to helping the young person & $\begin{array}{l}\text { - Amount of time or space } \\
\text { - Working with other teams or services } \\
\text { - Involvement of parents }\end{array}$ \\
\hline 4. Amount of training and resource & $\begin{array}{l}\text { - Previous understanding about mental } \\
\text { health } \\
\text { - Having to independently generate ideas }\end{array}$ \\
\hline 5. Helplessness and Satisfaction & $\begin{array}{l}\text { - Sadness and helplessness } \\
\text { - } \quad \text { Frustration } \\
\text { - Satisfaction and hope from helping }\end{array}$ \\
\hline
\end{tabular}

Table 1: The superordinate and subordinate themes generated from analysis 


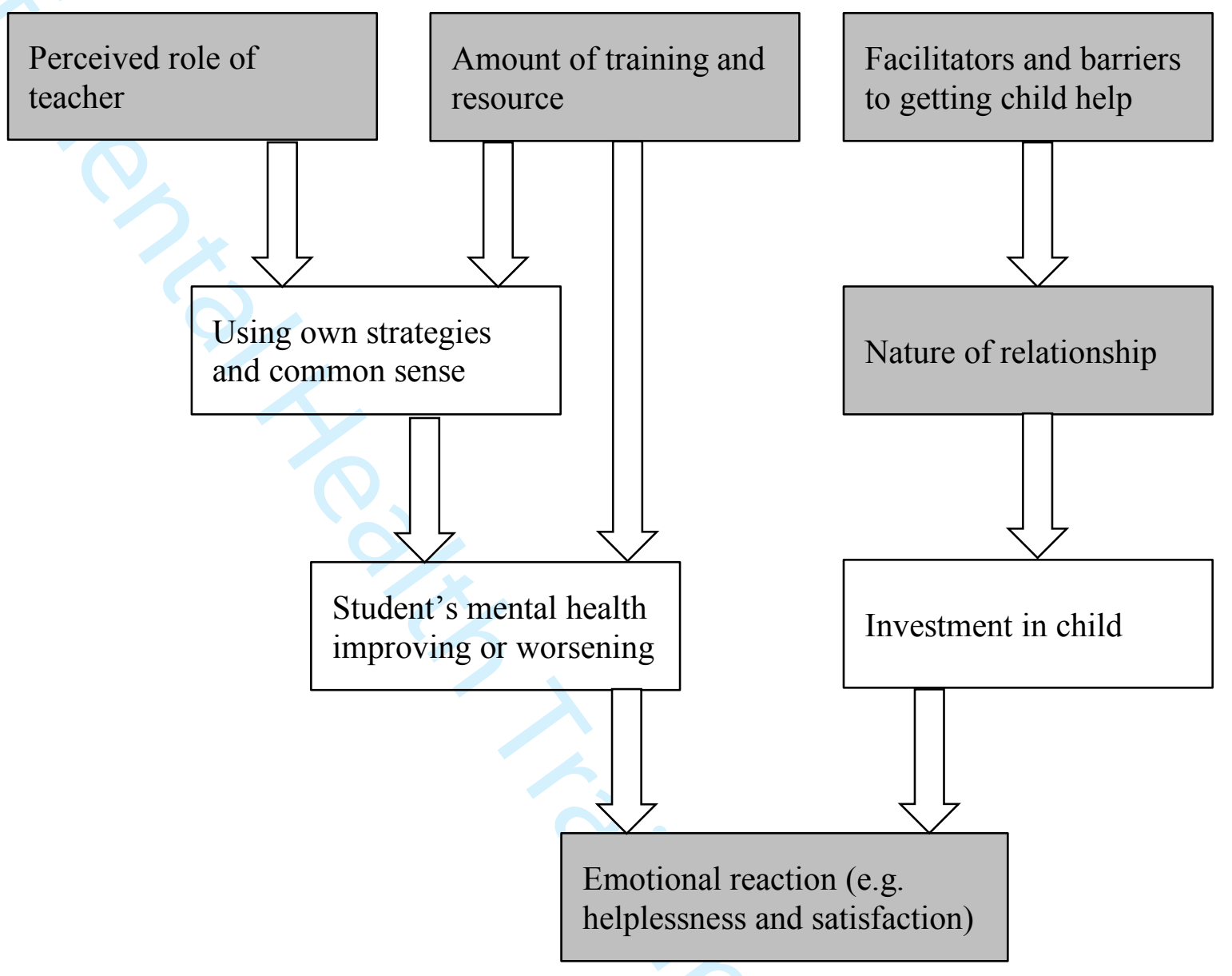

Figure 1. A theoretical model based of teacher's experience when supporting a student with a mental health problem. The grey boxes represent the five superordinate themes. 


.

.

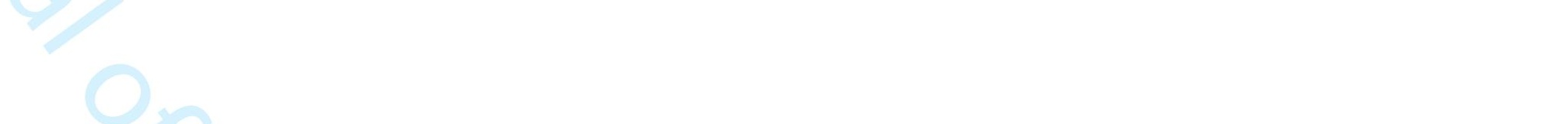

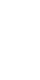

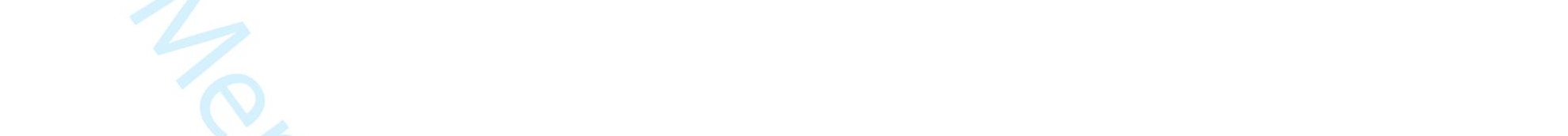

4

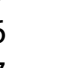

(1)

